and $g$, without its being so stated, is taken in inches per second per second.

A chapter headed "Testing of Electric Light Dynamos, Accumulators, and Transmission of Power," given at pp. I76-86, is not at all satisfactory. The tests for the efficiency of a secondary battery are neither clearly nor fully given, and the score of lines devoted to this important subject close with a most remarkable sentence, which we quote :- "The total work done in charging and discharging may also be measured by a suitable voltameter joined up as a shunt to the secondary battery, sn as to pass a known fraction of a current through it."

At p. 373 there are two or three misprinted formulas, but in the first line of p. 374 we have perhaps the most extraordinary equation ever given in a work on electrodynamics. The difference of potential at the terminals of a dynamo (a shunt-dynamo we presume is meant) is there stated to be equal alternatively to the product of the current in the field magnets multiplied into their resistance, to the current in the cxternal circuit multiplied into the resistance of the external circuit, and to the current in the armature multiplied into the resistance of the armature!

The calculation (p. 345) relative to the electrolytic decomposition of copper sulphate involves also serious theoretical errors. Mr. Jamieson, multiplying together the electro-chemical equivalent of copper and the heat of combination of copper and oxygen, makes the "electromotive force required to deposit copper from a solution of sulphate of copper" to be 836 volt. In the particular case, not however referred to, of a cell having a platinum anode and copper kathode, this would be the approximate electromotive force required on the ccll to produce electrolysis. But the author actually goes on to use this result as the electromotive force required on an ordinary electro-plating bath to effect the electrolysis, and bases on it some conclusions as to the efficiency of a Siemens machine depositing copper in commercial work, or in the stereotyping of ordinary printed matter. In these cases of course both anode and kathode are copper plates, and the calculated electromotive force has no application whatever.

A single remark on another subject we would makc before taking leave of this work. In many places where the compilers are under obligations to other authors due acknowledgment is wanting. For examples we may refer to several parts of the chapter on submarine telegraphy, to pp. 369-76 on dynamos and transmission of power, and to part of p. 403, where, by the way, the very serious errors inherent in the method of determining (?) the intensity of a magnetic field by counting the oscillations of a magnetic needle are not alluded to.

In conclusion we have no hesitation in saying that with a careful weeding of the tables, minute verification and correction of the algebraical work, deletion of a good deal of the "theory" given, and lastly, copious references to original sources, both as a matter of convenience to the user and of literary justice, this "Pocket-Book" will be made a very valuable vade mecum for elcctrical engineers. As it is, it will no doubt be found of service, but, as we have indicated, its statements must on several subjects be received with caution.

A. GRAY

The Non-Bacillar Nature of Abrus Poison. By C. J. H. Warden, Surgeon I.M.S., and L. A. Waddell, Surgeon I.M.S. (Calcutta, I884.)

THIS pamphlet is an exhaustive treatise on the nature, physiological and chemical properties of the seeds of Abrus precatorius, called Jequirity by the South Americans, and used to curc granular lids. As is now well known through de Wecker of Paris and Prof. Sattler, this popular remedy of the South Americans produces, when used as an infusion and applied to the conjunctiva, severe ophthalmia, in the course of which granular lid (trachoma) is brought to cure. In India it is used by the natives for subcutaneous injection into cattle, wherewith to produce a kind of septicæmia and death. The nature of the poison has been thought by de Wecker and Sattler, and later by MM. Cornil and Berlioz, to be due to a bacillus (the Jequirity bacillus), the spores of which are derived from the air; and, although harmless at first, assume pathogenic properties when grown in an infusion of the Abrus seeds. It has been conclusively proved, however, that this is not the case, that the active principle of the Abrus seeds is present before any contamination with the bacillus could have taken place, and further, that the Jequirity bacillus, when freed from the infusion, possesses no power of producing ophthalmia.

Messrs. Warden and Waddell have carefully examined the chemical nature of the seeds, and they find that the active principle, abrin, is a proteid, closely allied to native albumen, and obtainable not only from the seeds, but also from the root and stem.

E. K.

\section{A Text-Book of Pathological Anatomy and Pathogenesis.}

By Ernst Ziegler. Translated and edited for English students by Donald Macalister, M.A., M.B., \&c. Part II. Special Pathological Anatomy, Sections I.VIII. (London: Macmillan and Co., I884.)

THE enormous success that has attended the first part of this work will, we feel sure, in no way abate with the present volume. Like its predecessor it is a masterly exposition of all that is known concerning the pathological anatomy of the parts treated. In this last volume the special pathological anatomy of the blood and lymph, the vascular mechanism, the spleen and lymphatic glands, the serous mcmbranes, the skin, the mucous membranes, the alimentary tract, the liver and pancreas, are described with great clearness and thoroughness. The subjects are treated in a detailed and systematic way, without incumbrance with self-understood details. The illustrations are very admirable, and while not profuse, are nevertheless thoroughly representative. The bibliography, particularly of the more recent works, is, in the English edition, thanks to Dr. Macalister, a most valuable improvement on that in the German edition. While a help to the learner, it will no doubt prove also a valuable companion to the teacher.

E. K.

\section{LETTERS TO THE EDITOR}

[ The Editor does not hold himself responsible for opinions expressed by his correspondents. Neither can he undertake to return, or to correspond with the writers of, rejected manuscripts. No notice is taken of anonymous communications.

[The Editor urgently requests correspondents to keep their letters as short as possible. The pressure on his space is so great that it is impossible otherwise to insure the appearance even of communications containing interesting and novel facts.]

\section{The Late M. Dumas}

I HAVE received from M. Pasteur, President of the Committce, a letter informing me that it is proposed to erect a statue to the memory of Dumas at Alais, his native town. The name of Dumas is so prominent in the history of our science that no words of mine are needed in support of such a proposition, and I merely cxpress the hope that many English chemists will be willing to contribute to this memorial. Subscriptions will be receiver by the secretaries of the Chemical Society, Burlington IIouse, Piccadilly. W. H. PERKIN, P.C.S.

\section{The Cholera Germ}

THE latest enunciations of Prof. Koch from Toulon and Marseilles concerning the relation of his "comma-shaped" bacillus to cholera are so contradictory, that it is worth while to talse notice of them.

Koch, as was mentioned in your last issue (p. 237), maintains that the "comma-shaped" bacillus is the cause of cholera; and 